\title{
KAJIAN VISUAL IKLAN \\ MEDIA CETAK OTOMOTIF TAHUN 1960-1970
}

\author{
Fransisca Sherly Taju, Leony Agustine \\ Dosen Program studi Desain Komunikasi Visual, \\ Mahasiswa Program Studi Desain Komunikasi visual, \\ Jurusan Desain, FSR ISI Yogyakarta
}

\begin{abstract}
This research aims to find out the visual representation of automotive print advertising, duck motors of 1960 - 1970 from the socio-cultural side. Starting with data collection, sample selection, and analyzing sample results with visual interpretation according to Gillian Rose (2001: 18), namely: (1) site of the production of an image, (2) site of the image it self, (3) site where it is seen by various audiences. This visual interpretation is understood about (1) technology, photography and print. (2) Composition, here can be interpreted aesthetic work, and (3) social, here can be interpreted with visual meaning in print media advertising. This research is qualitative research with a case study analysis approach. Through this research provides knowledge of the history of photography that initially advertising print media using manual drawing techniques, then switching to using photography techniques. Initially the ad only showed the product, but in the 1960s, print advertising not only appeared colorfully but also presented a female figure to accompany the products offered, in this case is a duck motorcycle automotive product. The ad model is defined not only as a decorator of the ad field, but in context provides a code that the selected model is tailored to the popularity and accompanying cultural entity.
\end{abstract}

Keywords: automotive, print advertising, photography, visual communication

Relevance to Visual Communication Design Practice: The results showed that print technology has adapted to the needs of the field, especially in supporting the promotion and publication of producers of goods and services. Through this research it was revealed that the advance of print brought changes to the presentation and appearance of advertising styles and models, and also added to the variety of photographic studies related to socio-culture.

\section{PENDAHULUAN}

Awal mula otomotif di Indonesia dimulai dari kendaraan sepeda motor dengan sistem kopling yang dibawa oleh bangsa Eropa. Motor kopling hanya dipergunakan oleh kaum pria karena motor produksi Eropa/Amerika memiliki ukuran dan bentuk yang besar dan berat. Seiring berjalannya waktu muncul motor bebek yang dipelopori oleh motor-motor produksi Jepang yang salah satu fungsi dan tujuannya adalah ditujukan untuk kaum perempuan. Dalam rangka mempromosikan dan mengenalkan keberadaan motor bebek ini maka iklan yang ditampilkan pada saat itu menggunakan ilustrasi foto model perempuan dalam beberapa pose dan gaya mendampingi produk sepeda motor yang diiklankan.

Pertengahan tahun 1960, perkembangan perusahan periklanan semakin berkembang pesat terutama setelah pengesahan UndangUndang Penanaman Modal Asing (Setiyono, 2004: 15). Kebijakan perekonomian Orde Baru ini memberi dampak pada keterlibatan perusahaan multinasional untuk ikut menangani aspek promosi, karena tujuan mereka adalah memasarkan semua hasil 
industri yang ada. Sehingga revolusi industri yang juga membawa efek pada produksi barang, termasuk cetakan yang terus meningkat karena dapat diproduksi secara massal. (Kardinata, 2015:26).

Akhir tahun 60an dan awal 1970-an adalah masa transisi industri periklanan, yang pada mulanya didominasi teknik gambar tangan/hand drawing dan penggunaan cliché line hitam putih, yang bertahan hingga tahun 1940an.

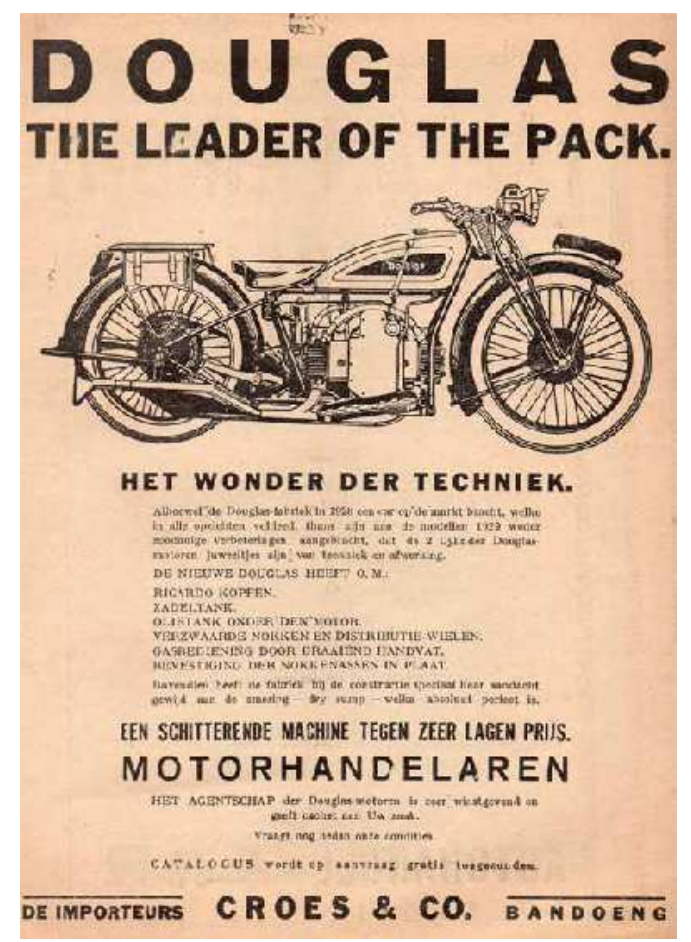

Gambar 1 Iklan sepeda motor dengan teknik cliche line hitam putih tahun 1930an

Sumber:https://www.pinterest.co.uk/pin/407505466 281810036/

Iklan-iklan komersial di media dimulai pada tahun 1968 yang disiarkan lewat surat kabar nasional seperti Kompas, Sinar Harapan di Jakarta, dan Pikiran Rakjat di Bandung. Sampai awal tahun 1970-an, pesan-pesan iklan body copy dituliskan panjang lebar dan mendominasi iklan secara keseluruhan. Hal ini dikarenakan produk konsumerisme cenderung masih baru dan masih belum banyak dikenal. Barulah di akhir tahun 1970an presentasi iklan Indonesia mulai berkembang seiring dengan perkembangan media dan teknologi.

Naskah atau copy iklan dan visualisasi mulai dipikirkan dengan baik. Pada periode ini mulai muncul dan berkembang simbolisasi dan personifikasi mendominasi presentasi iklan di Indonesia. Iklan tidak hanya menerapkan pendekatan demografis dalam mendekati calon pembeli. Adapun pendekatan psikografis mulai diterapkan dimana citra pariwara telah dihubungkan dengan gaya hidup atau life style mulai mendominasi visualisasi iklan demikian pula gaya bahasa dalam komunikasi periklanannya. (Soraya, 2019) Penelitian Iklan Media Cetak Otomotif Tahun 1960-1970 dengan sampel motor bebek ini penting untuk dikaji, karena merupakan cikal bakal iklan media cetak yang menggunakan teknik fotografi, di mana saat ini iklan cetak yang menggunakan teknik fotografi sudah mendominasi $100 \%$ di Indonesia. Hasil penelitian ini diharapkan dapat juga untuk menambah ragam kekayaan kajian fotografi yang berhubungan dengan sosial budaya dan awal iklan media cetak otomotif menggunakan model wanita.

Berdasarkan uraian latar belakang di atas, maka pertanyaan penelitian ini yakni bagaimana wujud iklan cetak warna otomotif era 1960-1970 ditinjau dari aspek konten pesan iklan cetak, visual fotografis iklan cetak, dan analisis kontekstual?

\section{STUDI LITERATUR}

Sebenarnya kapan sepeda motor yang pertama kali masuk Indonesia? Sejarah 
kendaraan bermotor di Indonesia telah dimulai sejak 126 tahun yang lalu ketika masih dijajah Belanda dan nama negara disebut Nederlands Indie (Hindia Belanda). Kendaraan bermotor bensin pertama adalah sepeda motor impor masuk ke tanah air (Hindia Belanda) pada tahun 1893 melalui Pelabuhan Semarang. Sebuah catatan menyatakan jika sepeda motor sudah hadir di Indonesia sejak jaman pendudukan Belanda pada tahun 1893 yang saat itu masih bernama Hindia Timur (Oost Indee).

Sebuah buku yang berjudul Krèta Sètan (De Duivelswagen) telah memuat catatan kisah bagaimana John C. Potter memesan sendiri sepeda motor tersebut, setelah membaca advertensi "motor bakar" bermerek Hildebrand und Wolfmüller di Muenchen, Jerman. Hal tersebut yang membuat Potter menjadi orang pertama di Indonesia yang menggunakan kendaraan bermotor.

Selang waktu hampir tujuhpuluh tahun setelah sepeda motor pertama di Indonesia tersebut, pada awal tahun 1960-an skuter Vespa masuk Indonesia yang kemudian diikuti sepeda motor asal Jepang, seperti Honda, Suzuki, Yamaha. Teknologi iklan, baik untuk produknya maupun model iklannya masih sangat sederhana, semata-mata hanya menampilkan gambar objek produknya. (https://www.otosia.com/berita/inilahsepeda-motor-pertama-yang-masukindonesia.html, diakses, 12 Juli 2021, pukul 11.35)

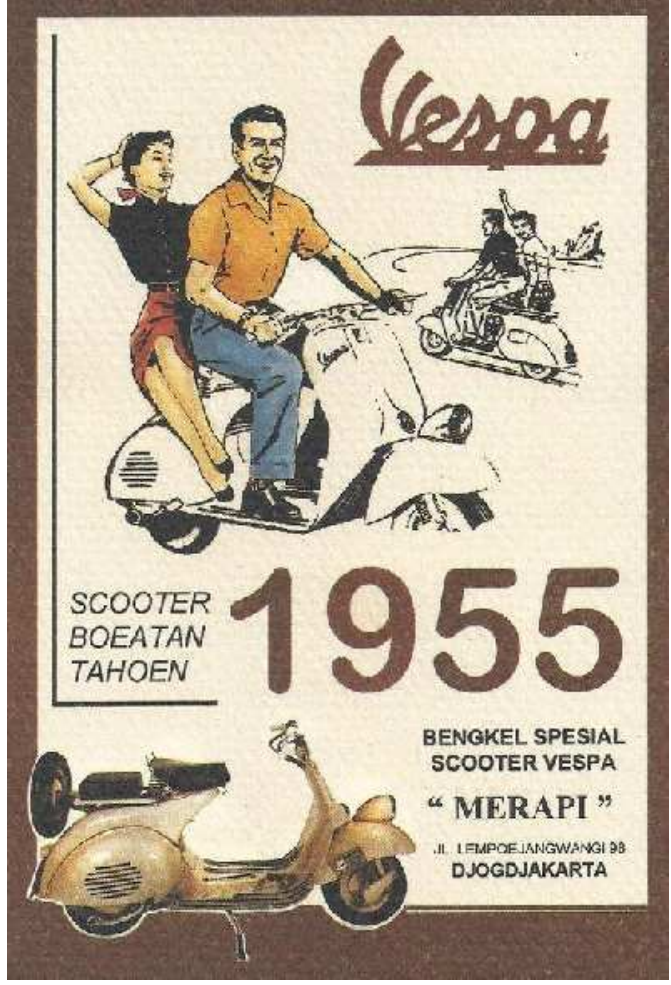

Gambar 2 Iklan cetak warna motor vespa, dengan teknik color block telah dirintis tahun 1955. Sumber:https://id.pinterest.com/pin/7975594152341 $39186 / /)$

Perkembangan teknologi reproduksi dari cetak tinggi atau press ke cetak offset, sedikit banyak telah meningkatkan kualitas gambar/foto pada iklan cetak berwarna. Cetak grafika iklan berwarna dipelopori oleh industri grafika Jerman dengan mesin cetak yang sudah terkenal sejak teknik cetak telah melanda Eropa yakni "Heidelberg". Gambar berwarna pun mulai muncul dalam iklan display.

Ukuran ruang yang digunakan juga meningkat hingga seperempat sampai setengah halaman. Teknologi cetak mesin warna telah mengarah penggunaan kamera dan pengenalan teknologi ke arah fotografi. Setidaknya terjadi peningkatan baik kualitas maupun penyajian iklan dimasa akhir tahun 1955 dan menjelang awal tahun 1960an. 


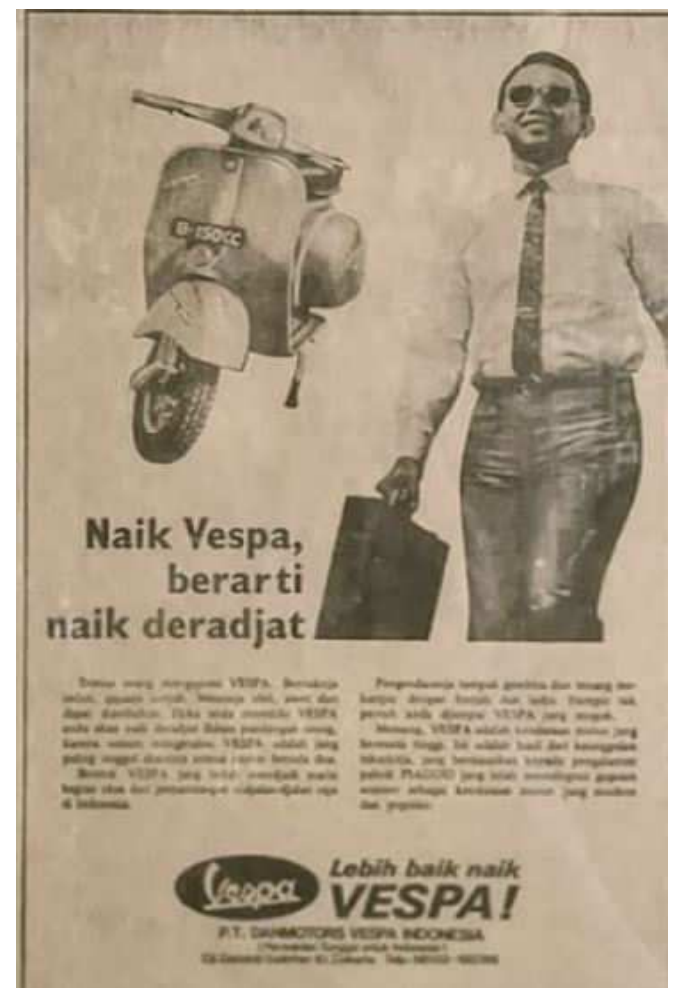

Gambar 3 Iklan cetak hitam putih, dengan teknik cliché raster telah dirintis awal tahun 1960an.

Sumber:https://enoanderson.com/2015/10/10/specia l-sejarah-vespa-di-indonesia)

Meskipun jika diukur dengan teknologi hari ini, cetak warna tersebut dinilai sangat sederhana, namun setidaknya telah dapat mendekatkan objek produknya dapat meyakinkan publik. Teknik warna yang digunakan pada awal rintisan iklan warna, saat itu belum menggunakan raster, sehingga terasa janggal untuk ukuran hari ini, karena objek iklan tidak mengenal dimensi, semua tampak datar/flat.

\section{KAJIAN PUSTAKA}

Kajian pustaka sangat diperlukan dalam sebuah penelitian, terutama untuk menilai keaslian topik yang akan dikaji dan juga membantu sebagai bahan acuan dalam penulisan penelitian. Ada beberapa tulisan yang mendekati permasalahan yang serupa dengan peneliti. Penelitian Terdahulu, pertama tulisan dari Harsanto (2016), melalui penelitian disertasinya yang menghasilkan buku berjudul "Retorika Visual Fotografis dalam Iklan Koran", mengkaji iklan koran Kompas dari rentang tahun 1965-2009 dengan memilih iklan display, sehingga dapat mengkategorikan tiga visualisasi dalam iklan, yakni: gaya informasi produk (tahun 19651970-an), simbol pencitraan (tahun 1980 1990-an), dan ekspresi pengalaman (tahun 2000an). Kajian ini dikupas sesuai tatanan sosial-budaya dan politik pada momen historis, sehingga menciptakan gaya atau jiwa zaman.

Kedua, paparan Rohman (2015), melalui penelitian Skripsi yang berjudul "Perkembangan Iklan Media Cetak dan Pengaruhnya Terhadap Modernisasi di Jawa (1930-1942)", penelitian tersebut membahas sejarah awal, perkembangan, dan pengaruh iklan media cetak terhadap modernisasi di pulau Jawa pada periode tahun 1930-1942. Hasil penelitian diperoleh sejarah awal periklanan, yakni ketika terbitnya surat kabar Bataviasche Nouvelles tahun 1744 yang sebagian besar berisi iklan perdagangan, pelelangan, dan pengumuman pemerintahan VOC. Seiring berjalannya waktu pada tahun 1870 pemodal asing berlomba-lomba berinvestasi di Hindia Belanda, sehingga iklan makin banyak bermunculan.

Ketiga, tulisan Banindro dalam Jurnal DeKaVe Vol. 1 No. 1 Januari 2011 dengan judul "Tinjauan Sosiohistoris Iklan Masa Kolonial (1930-1942)" mengungkap bahwa sejarah peradaban suatu masyarakat dapat dilihat melalui iklan pada masa itu melalui bahasa visual. Iklan masa kolonial memberikan pandangan pada pribumi akan 
produk barat dan budayanya. Adanya kebudayaan kolonial yang hadir maka memperkaya kebudayaan Indonesia, termasuk di dalamnya gaya desain grafis.

Keempat, tulisan Kertamukti (2010) dalam Jurnal ASPIKOM Vol. 1 No.1 bulan Juli, dengan judul "Komunikasi Visual Iklan Cetak Rokok di Indonesia Kurun Waktu 1950 - 2000" mengungkapkan bahwa perkembangan iklan media cetak turut bergerak menyesuaikan teknologi komunikasi yang ada pada saat itu. Terlihat dalam perkembangan komunikasi visual iklan cetak produk rokok di Indonesia dalam periode awal bermunculan sebagai produk yang massif hingga sekarang yang dinilai dari unsur-unsur komunikasi visual yang membentuknya, seperti tipografi, warna, gambar, layout serta pendekatan semiotikanya.

Dua tinjauan pustaka milik Rohman dan Banindro memiliki kesamaan topik dan sudut pandang dengan peneliti, yakni perihal iklan media cetak yang dilihat dari sudut pandang karakter iklan dan sosial budaya pada saat itu. Namun rentang tahunnya jauh sebelum topik penelitian yang akan diangkat. Tinjauan pustaka milik Kertamukti memiliki kesamaan sudut pandang dalam menilai sampel penelitian, yakni menitikberatkan pada unsurunsur komunikasi visualnya. Namun topik Kertamukti sangat berbeda yakni tentang iklan rokok, sedangkan penelitian yang yang akan dilakukan ini adalah tentang iklan otomotif. Tinjauan pustaka milik Harsanto yang paling mendekati tahun topik penelitian ini, namun pada penelitian Iklan Media Cetak Otomotif Tahun 1960-1970 lebih spesifik, sehingga penelitian ini menghasilkan pengetahuan asal muasal tentang iklan media cetak yang menggunakan teknik fotografi fullcolor serta dikaji melalui fenomena sosial budaya wanita dan termasuk adanya perubahan politik yang melekat pada saat itu. Berdasarkan uraian di atas, maka topik penelitian penulis berbeda dari tiga penelitian sebelumnya.

\section{Landasan Teori}

Adapun permasalahan dalam penelitian ini yang berkaitan dengan periklanan, dan perempuan. Periklanan secara umum dapat diartikan sebagai taktik untuk memikat audience melalui berbagai strategi, serta mengevaluasinya, sehingga dapat menganalisis efektivitas komunikasi antara source dan decoder. Sehingga periklanan merupakan bentuk komunikasi yang dilakukan oleh pengiklan untuk mengkomunikasikan sesuatu kepada konsumen melalui media (Santosa, 2009: 1). Lebih lanjut Budi menjelaskan bahwa trend kreativitas periklanan di era ini ditandai dengan terfokusnya inti pesan iklan pada kebutuhan untuk mengumumkan keberadaan atau ketersediaan produk di pasar (Setiyono, 2004: 13).

Menurut Rittlinger (1972) fisik perempuan memiliki daya tarik tersendiri. Tidak heran bila menjadi sasaran favorit berbagai pihak dan profesi, baik fotografer, kameramen, pengiklan, pemasar, dan sebagainya. Daya tarik tersebut memang sangat khas, unik, dan spesifik yang tidak bisa ditemukan pada pria. Sedemikian menariknya perempuan sehingga menurut Mulvey dalam Widyatama (1981), perempuan telah menjadi ikon di media massa. Analisis konten mengungkap pesan iklan melalui simbolsimbol yang digunakan, seperti model, 
kostum, ekspresi, teknik kamera, dan pencahayaan.

Media cetak adalah suatu media yang statis dan mengutamakan pesan-pesan visual. Media cetak memiliki karakteristik yang bersifat fleksibel, mudah dibawa ke manamana bisa disimpan (dikliping), bisa dibaca kapan saja, tidak terikat waktu. Dalam hal penyajian iklan, walaupun media cetak dalam banyak hal kalah menarik dan atraktif dibanding media elektronik namun di segi lain bisa disampaikan secara informatif. (Hereyah 2014: 169 - 184 ) Iklan Media Cetak adalah suatu pesan media yang statis dan mengutamakan pesan-pesan visual. Media ini terdiri dari lembaran dengan sejumlah kata, gambar atau foto, tata warna dan halaman putih. Pada umumnya unsur-unsur iklan pada media cetak terdiri dari : headline, subhead, body text, splash, closing word, caption, brand name, logo tipe, gambar (ilustrasi atau fotografi) dan slogan.

Kesepuluh unsur iklan ini merupakan satu kesatuan dalam iklan, namun semua unsur-unsur tersebut tidak selalu dipakai secara berurutan pada sebuah iklan, karena yang utama adalah bagaimana iklan dapat menunjukkan keserasian dan kesatuan dari hasil kreatif desainer dalam menyampaikan pesan. (Kertamukti 2010: 1-124) Sedangkan unsur-unsur komunikasi visual diantaranya terdiri dari tipografi (headline, subhead, body text), warna, gambar, layout (simetris, asimetris). (Margolin, 1989).

Analisis visual mengungkapkan komposisi elemen utama dalam iklan, sedangkan analisis kontekstual merupakan analisis wacana yang dikaji dari konteks sosial budaya (Harsanto, 2016: 34). Hal ini juga ditinjau dari intepretasi visual menurut Gillian Rose (2001), yakni memiliki tiga ranah:

(1) site of the production of an image, (2) site of the image it self, (3) site where it is seen by various audiences. Intepretasi visual ini dipahami tentang (1) teknologi, di sini dapat diartikan sebagai fotografi dan cetakan. (2) komposisi, di sini dapat diartikan estetika karya, dan (3) sosial, di sini dapat diartikan dengan makna visual di iklan media cetak.

\section{METODE PENELITIAN}

Penelitian ini menggunakan pendekatan kualitatif dengan proses analisis studi kasus. Menurut Merriam (2009) penelitian kualitatif meliputi berbagai teknik interpretasi yang berusaha untuk mendeskripsikan, 'membaca' kode, menerjemahkan, dan di samping itu bisa memahami makna, dari berbagai fenomena yang secara alamiah ada di dunia sosial. Sedangkan studi kasus adalah suatu upaya melakukan deskripsi dan analisis yang mendalam (in-depth) dari kasus tersebut. Diawali dengan pengumpulan data, data menjadi faktor yang sangat utama dalam penelitian, sehingga diperlukan sumber data primer dan data sekunder. Data berupa iklan media cetak pada tahun 1960 - 1970.

\section{HASIL PENELITIAN}

Analisis Gillian Rose Iklan Sepeda Motor Bebek (Era 1960-1970an). Penelitian ini pada dasarnya adalah penelitian deskriptif analisis, yang mendasarkan pada studi kasus, yakni pada objek jenis iklan fotografis berwarna. Iklan yang dimaksudkan adalah gambar sepeda motor produk Jepang yang diimpor oleh distributor otomotif di Indonesia dan memuat gambar perempuan yang diterapkan pada objek komersial 
khususnya produk otomotif motor bebek full electric, yang pernah dicetak di berbagai media di Indonesia antara tahun 1960 hingga 1970. Dari hasil populasi yang telah ditetapkan dan penetapan sampel maka diperoleh analisis sebagai berikut:

\section{a. Identifikasi Objek Formal.}

1) Poster Iklan Suzuki FR80 (Family)

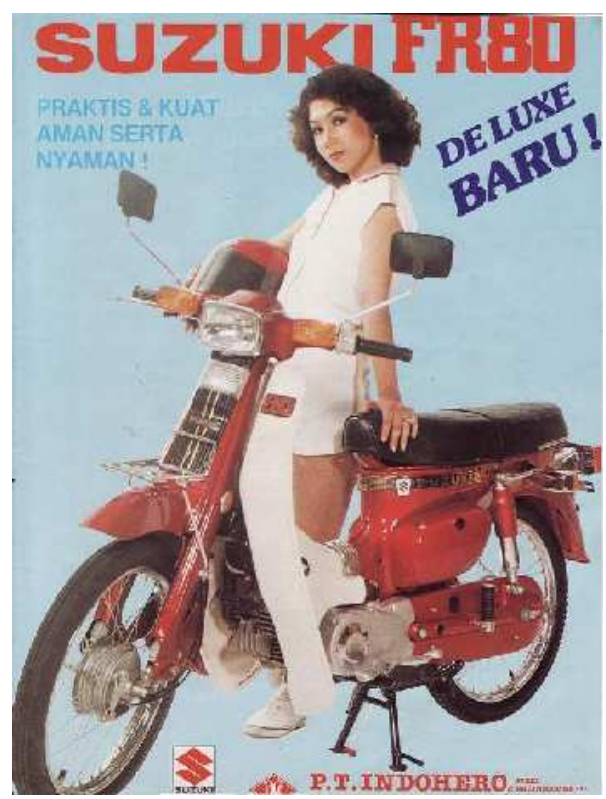

Gambar 4 Poster iklan suzuki fr80 1970 Sumber: https://imotorium.com/2020/03/19/mesinlegendaris

a) Site of the production of an image, (produksi gambar) Poster iklan Suzuki FR80 pada gambar 12 dirancang oleh biro iklan Intervista tahun 1969-1979, dicetak berwarna (full color) di atas kertas art papper ukuran A3 ( $30 \times 40 \mathrm{~cm})$.

b) Site of the image it self, (gambar itu sendiri) Gambar utama poster iklan menampilkan sosok artis Dana Christina, lahir di ذakarta, 28 Juli 1957, adalah pemeran film layar lebar Indonesia di era tahun 1970-an. Aktris berdarah Indo ini pernah mendapatkan nominasi Piala Citra dalam film "Lebak Membara" pada tahun 1984. Semasa kariernya ia membintangi puluhan film Nasional. Beberapa diantaranya adalah "Pasukan Berani Mati", "Dendam Manusia Harimau", "Kabut Sutra Ungu", dan "Wajah Tiga Perempuan". (https://kumparan.com/ilhambintang/artis-dana-christina 1w8h8RJmL39/full, diakses 12 Juli 2021, pukul 23.34)

c) Site where it is seen by various audiences. (aspek audiens) Dalam sebuah laman Facebook, pemilik akun bernama Antoni mengomentari bahwa poster motor jadul ini bikin netizen salfok. Dalam forum 2 April 2019 berjudul INDONESIA TEMPO DOELOE yang diakses 13 Juli 2021, pukul 18.08, Ia membagikan postingan dengan caption bertuliskan "Motor jadul emang masih mantep pol kualitasnya, ngak kayak motor2 zaman sekarang". Banyak netizen zaman old yang masih ingat keberadaan motor ini ketika masih hype di zamannya. Postingan yang dibagikan cukup membuat netizen heboh setelah mendapatkan lebih dari 1.400 Like dan ratusan komentar beragam dari netizen. (Netizen Bagikan Poster Motor Jadul, Hal ini Auto Telah Bikin Nostalgia!https://themarquisblogger. wordpress.com/2015/08/20/suzukifr80) Ini menunjukkan bahwa poster iklan motor Suzuki ini mampu 
membawa kenangan masa jaya motor di benak audien, diakses 29 Juli 2021, pukul 14.11).

\section{b. Intepretasi Objek Material}

1) Teknologi, (fotografi dan cetakan)

Teknik pemotretan iklan ini tergolong baik, objek pengambilan gambar dilakukan in door studio dengan posisi vertical grid. Teknik close up dengan sudut pandang angle semi frog eye dipilih untuk menyajikan iklan Suzuki FR80 tersebut. Melihat hasil akhir poster iklan tersebut terlihat dicetak dengan mesih offset kualitas tinggi high resolution $175 d p i$ (dot per inchi), hal ini dibuktikan resolusi padat dan tidak pecah saat diperbesar gambarnya.

\section{2) Komposisi, (estetika karya)}

Secara umum komposisi iklan baik teks maupun ilustrasi foto disajikan dengan tata letak (layout) simetris vertikal di atas blatar berwarna biru. Elemen iklan terdiri atas head line dengan judul: SUZUKI FR80, menggunakan jenis huruf gabungan san serif bold dan serif Egyptian berwarna merah, teks body copy san serif Helvetica berwarna biru berisi hadirnya jenis seri terbaru dan keunggulan sepeda motor buatan Honda, poster iklan diakhiri dengan clossing nama importir dan dealer: Sole Distribution: PT INDOHERO. INC, dengan logo Suzuki dan dealer sepeda motor.

Pemilihan warna headline dengan warna merah untuk memberikan eye catching bagi audien, penggunaan huruf san serif bold dan serif Egyptian memberikan kesan kokoh dan tangguh tentunya merujuk pada produk merek sepeda motor bebek Suzuki. Penulisan teks (body copy) isi iklan font San Serif Helvetica dengan warna biru muda dan tua di atas bidang cetak warna biru tentunya dimaksudkan untuk menghasilkan harmoni warna agar nyaman dibaca oleh audien.

Pemilihan objek baik model maupun detail sepeda motor seperti helem full face dan penutup rantainya, membuktikan orang dulu lebih jauh memikirkan keselamatan dan kenyamanan penggunanya, motor zaman dulu pasti ada penutupnya semua, tidak seperti dengan jaman sekarang.

3) Sosial, (makna visual iklan)

Visualisasi poster iklan secara umum mencerminkan gaya hidup to date. Setelan jump suite putih lengan pendek dan celana sporty pendek warna putih dan paduan sepatu kets warna putih menunjukkan representasi elegan dan branded.

Tatanan rambut dan dandanan make up menunjukkan gaya atau mode konsumtif yang sedang melanda Indonesia sesuai peningkatan taraf hidup dan perekonomian. Cincin berlian di jari manis menunjukkan bahwa status sosial tinggi dan berada.

Secara umum poster iklan ini tampil sempurna dalam mengenalkan produk baru di masyarakat di era ini. Suzuki sangat memperhatikan safety ridding bagi konsumennya. 
2) Poster Iklan Honda C 70 Super Cub

a) Intepretasi Objek Formal

(1) Site of the production of an image, (produksi gambar) Poster iklan Honda C70 dirancang oleh biro iklan Intervista tahun 1969-1973, dicetak berwarna (full color) di atas kertas art papper ukuran A3 ( $30 \mathrm{x}$ $40 \mathrm{~cm})$.

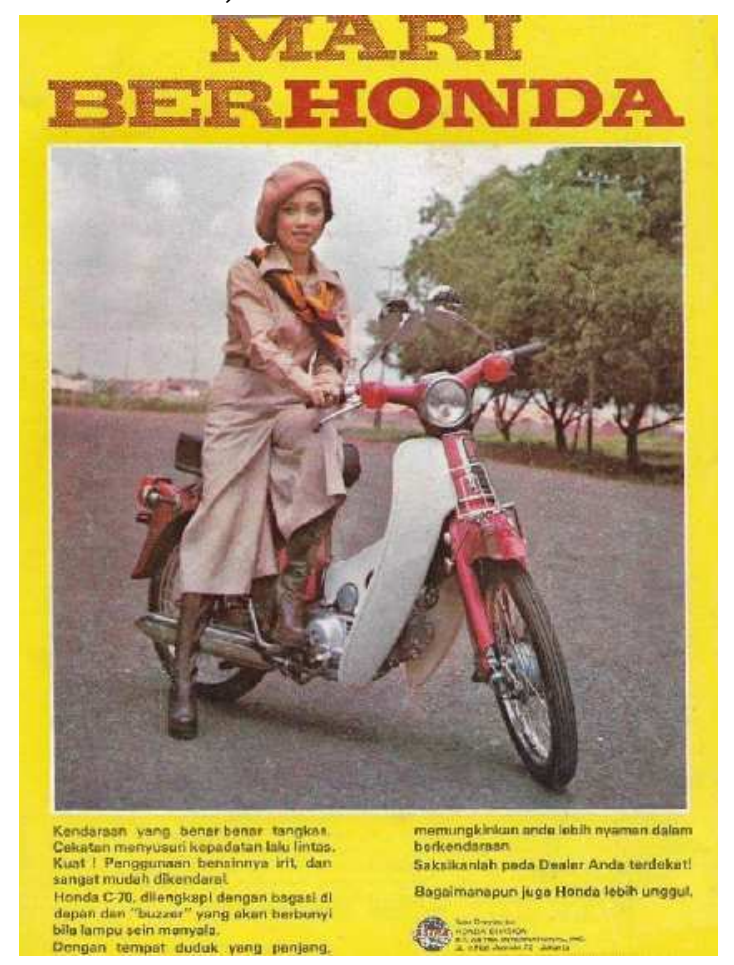

Gambar 5 Poster iklan honda c70 tahun 1970 Sumber:https://imotorium.com/2020/03/19/mesinlegendaris

(2) Site of the image it self, (gambar itu sendiri) Gambar utama poster iklan menampilkan sosok artis penyanyi asal Bandung Iin Parlina, yang merupakan salah satu personel dari grup musik asal Indonesia, Bimbo. (Yayang rudian. "Iin parlina profile". Kompas.com. Diakses tanggal 6 April 2021, 11.34) Sosok model iklan Iin Parlina, digambarkan duduk bertumpu dengan satu kaki di atas motor Honda C70 warna merah kanan menyamping ke arah kanan menghadap audien. Model iklan ditampilkan mengenakan mantel dress coat style warna ochre (khaki) dan topi barret warna serupa serta scraf slayer warna-warni diikatkan di badan, sepatu boot kulit warna coklat tua (dark brown).

(3) Site where it is seen by various audiences. (aspek audiens) Dalam penelitian ini poster iklan Honda diperoleh dari unggahan Ahmad Muzaki Selasa, 30 Juni 2020 12:15, berjudul Iklan Jadul 'Si Pitung', Motor Bebek Honda yang Legendaris, seorang motovlog dan gambar poster orisinal diperoleh dari@Instagram/@rayuaniklan. Dalam salah satu ulasannya menyampaikan bahwa produk poster iklan Honda ini termasuk barang langka dan menjadi buruan para kolektor iklan jadul (jaman dulu) atau iklan lawas. Generasi di atas tahun 1980an akan selalu mengenang dan memberikan julukan sepeda motor Honda C70 dengan sebutan "Si Pitung" serapan dari singkatan bahasa Jawa Si Pitung Puluh (sosok tujuh puluh cc).

\section{b) Intepretasi Objek Material}

(1) Teknologi, (fotografi dan cetakan) Teknik pemotretan iklan ini tergolong baik, objek pengambilan gambar dilakukan out door dengan posisi vertical grid sehinga diperoleh pencahayaan maksimal siang hari (daylight) yang memadai. Teknik close 
up dengan sudut pandang angle human eye dipilih untuk menyajikan iklan Honda C70 tersebut.

(2) Komposisi, (estetika karya) Secara umum komposisi iklan baik teks maupun ilustrasi foto disajikan dengan tata letak (layout) simetris vertikal di atas background berwarna kuning. Elemen iklan terdiri atas head line dengan judul: MARI BERHONDA menggunakan jenis huruf serif bold Egyptian berwarna merah, dan teks body copy san serif Helvetica berwarna hitam berisi penjelasan teknis dan keunggulan sepeda motor buatan Honda, poster iklan diakhiri dengan clossing nama importir dan dealer: Sole Distribution HONDA DIVISON: PT ASTRA INTERNATIONAL. INC, Jl. Ir. Haji Juanda 72, Jakarta dilengkapi dengan logo ASTRA. Pemilihan warna headline dengan warna merah untuk memberikan perhatian kuat secara optis, pemilihan font Bold Serif Egypt memberikan kesan kokoh dan tangguh tentunya merujuk pada produk merek sepeda motor bebek Honda. Penulisan teks (body copy) isi iklan font San Serif Helvetica dengan warna hitam di atas bidang cetak warna kuning tentunya dimaksudkan untuk menghasilkan kontras warna agar mudah dibaca oleh audien. Penempatan dan pemilihan objek baik model maupun sepeda motor menghadap audien dengan posisi serong (en profil) tampak pandangan depan sebelah kanan dimaksudkan untuk memperjelas detil objek baik apa yg dikenakan model ataupun dimensi produk sepeda motor
Honda C70. Poster iklan ini secara keseluruhan menunjukkan harmoni antar elemen sehingga nyaman dilihat dan estetik.

(3) Sosial, (makna visual iklan) Mantel dress coat style (mix and match) yang dikenakan secara konsep adalah model pakaian wanita paduan antara blouse jacket dan rok celana, berfingsi melindungi tubuh agar tetap hangat, sekaligus bagian dari gaya busana. Model mantel dipakai sebagai padanan fashion eksklusif, mantel biasanya berlengan panjang dan memiliki bukaan di depan yang bisa ditutup dengan kancing atau ritsleting, velcro, sabuk atau kombinasinya.(https://www.fimela.co $\mathrm{m} /$ fashion-style, diakses 12 Juli 2021, pukul 14.14) Sepatu boot dalam iklan Honda terlihat berbahan kulit adalah kelengkapan perempuan di Eropa untuk shopping ataupun travelling kelana dunia, simbol kualitas dan barang berkualitas tinggi dengan harga selangit. Barret yang dikenakan meski cukup sederhana, tapi baret dianggap cantik. Umum dikenakan sebagai bagian fesyen klasik kaum wanita di Eropa, baret muncul dalam dunia kreatif, banyak dipakai oleh penulis, penyair, dan bintang film, kini barret merupakan simbol perempuan yang memiliki selera fesyen tinggi. (https://www.suara.com/lifestyle/20 19/01/11/065500/baret-topi-militeryang-bertransformasi-jadi-itemfesyen, diakses 19 Juli 2021, pukul 14.14) 
Makna visual poster iklan yang disajikan oleh biro iklan Intervista pada produk ini adalah ingin memposisikan sang pemilik motor bebek Honda C70 menjadi bagian gaya hidup moderen dan fashionable serta berkelas di stara sosial atas.

\section{3) Poster Iklan Yamaha V70 Mate}

\section{a) Intepretasi Objek Formal}

(1) Site of the production of an image, (produksi gambar) Poster iklan Yamaha V70, dirancang oleh biro iklan Intervista tahun 1970-1975, dicetak berwarna (full color) di atas kertas art papper ukuran A3 ( $30 \times 40$ $\mathrm{cm}$ ).

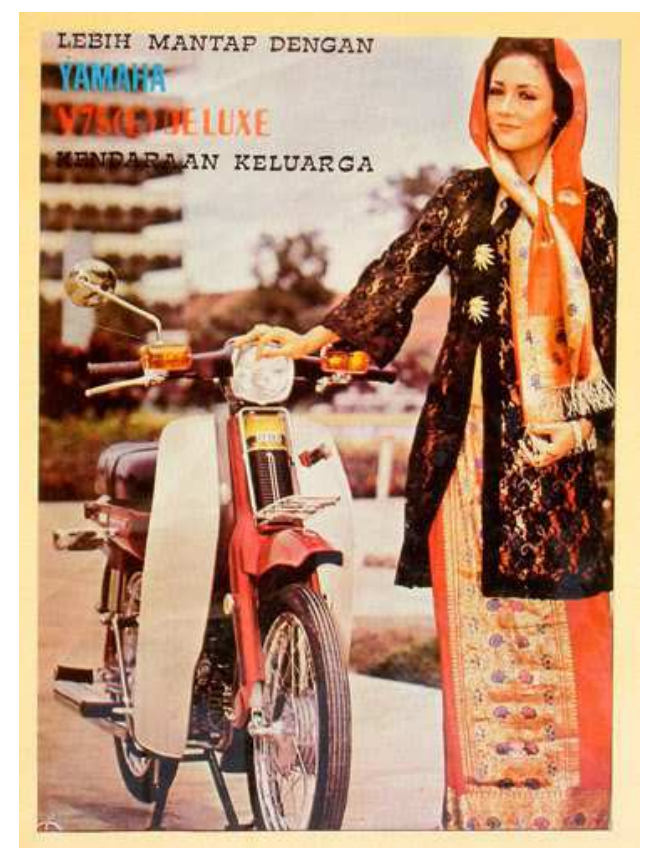

Gambar 6 Poster iklan Yamaha 75 tahun 1970. Sumber:https://imotorium.com/2020/03/19/mesinlegendaris)

(2) Site of the image it self, (gambar itu sendiri) Gambar utama poster iklan menampilkan sosok artis penyanyi era 1970an, Maria Yosepha Sri Sukartanti, atau lebih dikenal dengan nama Tanty Yosepha, lahir di Solo, Jawa Tengah, 22 Maret 1950. Dunia film ditekuninya dengan film lejit debutnya antara lain film Ratapan Anak Tiri produksi 1973 yang dibintanginya meledak (box office) di gedung-gedung bioskop.. (http://www.musictime.nl/indonesia/joseph a) Sosok model iklan Tanty Yosepha, digambarkan berdiri di samping kanan dengan tangan kanan menempel di atas sepeda motor Yamaha V70. Model iklan ditampilkan mengenakan pakaian kebaya tradisional Betawi lengkap dengan kerudung. Posisi motor dan model berdiri di depan bangunan gedung bertingkat.

(3) Site where it is seen by various audiences. (aspek audiens) Seperti diungkap oleh motorvlogg Isfandiari, 18 February 2019. dalam ungghan yang mengomentari poster iklan Yamaha V70 jaman dulu: di sebuah masa di pertengahan tahun 70an, underbone ini sungguh keren dan ciamik. Cewek cakep atau jejaka keren melintas di tempat gaul cihuy banget deh!. Iklan di jaman itu juga keren., bintang film kelas wahid turut menyebarkan virus asyiknya nyempak si garputala Yamaha produk Jepang ini. (https://ridingread.com/yamaha-v-seriesautolube-v50-v75-v80-underbone-keren-dimasanya-by-c-pi) Demikian pula netizen bernama Heri mengomentari pendek iklan lawas itu. Iklan motor jadul Yamaha V70, adalah sebuah motor yang sungguh mempesona dan mengagumkan di zamannya.(https://setial heri.com/2014/02/0 9/iklan-motor-yamaha-jadul-gan/ diakses 17 Juli 2021, pukul 16.32) Dari ulasan pendek itu dapat disimpulkan bahwa Yamaha sangat dikenal dan popular bagi kalangan anak muda, walau hanya sekedar melihat poster 
iklannya sudah cukup meyakinkan bahwa produk Yamaha memberikan positioning dan segmented di masyarakat.

\section{b) Intepretasi Objek Material}

(1) Teknologi, (fotografi dan cetakan) Teknik pemotretan iklan ini berkualitas baik, objek pengambilan gambar dilakukan out door dengan posisi vertical grid sehinga diperoleh pencahayaan maksimal siang hari (day light) yang memadai. Teknik close up dan semi deep of field dengan sudut pandang angle human eye dipilih untuk menyajikan iklan Yamaha V70 tersebut.

(2) Komposisi, (estetika karya) Pengambilan objek dengan teknik deep offield menjadikan objek gambar focus pada benda dan model iklan. Desain iklan disajikan dengan tata letak (layout) simetris vertikal $\mathrm{di}$ atas background existing bangunan. Elemen iklan terdiri atas head line dengan judul: LEBIH MANTAP DENGAN YAMAHA V70 DELUXE menggunakan jenis huruf serif Regular Egyptian berwarna biru, dan teks body copy san serif Helvetica berwarna biru tua berisi kebutuhan sepeda motor bebek tersebut untuk keluarga. Poster iklan tidak dilengkapi dengan clossing nama importir dan dealer. Pemilihan warna headline dengan warna biru tua untuk memberikan perhatian kuat secara optis, pemilihan font Regular Serif Egypt memberikan kesan produk sepeda motor bebek Yamaha. Penulisan teks (body copy) isi iklan font San Serif Helvetica dengan warna biru dan brand produk warna oranye di atas bidang cetak warna biru menghasilkan kontras warna sehingga mudah dibaca oleh audien. Penempatan dan pemilihan objek baik model maupun sepeda motor menghadap audien dengan posisi semi potret (tampak depan). Poster iklan ini secara keseluruhan menunjukkan objek produk Yamaha menjadi elegan dan mewah.

(3) Sosial, (makna visual iklan) pakaian yang dikenakan model iklan adalah busaha khas perempuan Betawi, dan kebaya itu umum biasa disebut dengan kebaya encim. Ciri kebayanya ada pada bagian depan bawah tanpa kancing sehingga dapat tersibak angin. Baju kebaya encim biasa dipadukan dengan kain motif rebung atau tumpal. Pada bagian kepala umumnya dilengkapi dengan selembar kerudung yang jatuhnya ditalikan atau dililitkan di bagian depan dada. Sepeda motor Yamaha V70 sebagai kendaraan keluarga roda dua yang mudah dikendarai kaum perempuan. Makna visual poster iklan Yamaha V70 adalah ingin menyampaikan pesan bahwa Yamaha bebek V70 adalah kendaraan yang lekat dengan masyarakat. Sosok perempuan dalam iklan ini dimaksudkan agar masyarakat mengerti bahwa motor bebek ini aman dan mudah dioperasikan kaum perempuan, pakaian adat kebaya yang dikenakan menunjukkan bahwa secara emansipasi tidak menyalahi kodrat dan dapat diterima dari aspek budaya lokal.

\section{KESIMPULAN}

Penelitian ini merupakan penelitian awal terkait teknik dan gaya visual iklan fotografis di media cetak. Sebagaimana 
perkembangan iklan cetak komersial otomotif, pada awalnya berupa gambar hitam putih menggunakan cliché lijn kemudian klise beraster. Seiring perkembangan jaman, maka teknologi cetak telah menyesuaikan dengan kebutuhan lapangan, khususnya dalam mendukung promosi dan publikasi para produsen barang maupun jasa. Melalui penelitian ini terungkap bahwa kemajuan cetak tersebut membawa perubahan pada penyajian dan penampilan gaya dan model iklan.

Pada awalnya iklan hanya mempertontonkan produk, namun di era 1960an, iklan cetak tidak hanya tampil dengan warna-warni namun juga menghadirkan sosok perempuan untuk mengiringi produk yang ditawarkan, dalam hal ini adalah produk otomotif sepeda motor bebek. Mengutip apa yang pernah dibahas dalam buku Sejarah Periklanan di Indonesia (2004), dasawarsa 1970an juga ditandai dengan tampilanya selebritis Indonesia sebagai bintang iklan. Model iklan dimaksdukan tidak hanya sekedar penghias bidang iklan, namun secara konteks memberikan kode bahwa model yang dipilih disesuaikan dengan popularitas dan entitas budaya yang menyertainya.

Melalui sajian mode dan gaya dengan apa yang telah ditampilkan oleh model perempuan, dalam iklan cetak warna otomotif 1960-1970, telah dapat memberikan catatan dan kronik bagaimana teknologi grafika masuk ke ranah media dan membawa dimensi dalam perkembangan periklanan di Indonesia. Sosok model dengan segala atribut yang dikenakan, seperti pilihan fashion, gaya rambut dan asesoris lain yang melekat pada bintang iklan, telah ikut mewarnai popularitas produk sepeda motor bebek Suzuki, Honda dan Yamaha, yang saat itu digandrungi di kalangan anak muda. Iklan media cetak warna era 1960-1970an, pada akhirnya mampu menjadikan simbol gaya hidup bagi keluarga pemilik sepeda motor bebek yang menjadi pilihannya.

\section{DAFTAR PUSTAKA}

\section{Buku}

[1] Harsanto, PW. 2016. Retorika Visual Fotografis dalam Iklan Koran. Yogyakarta: Kanisius

[2] Kardinata, H. 2015. Desain Grafis Indonesia 1. Jakarta: DGI Press

[3] Margolin, V. 1989. Design Discourse: History, Theory, Criticism: University of Chicago Press; 1st edition

[4] Merriam, SB. 2009. Qualitative Research : A Guide to Design and Implementation. San Francisco : John Wiley \& Sons, Inc.

[5] Palupi, DH \& Pambudi, TS. 2006. Advertising that sells. Jakarta: Gramedia Pustaka Utama

[6] Rittlinger, Herbert. 1972. The Photographer and The Nude. Great Britain: The Focal Press.

[7] Rose, Gillian. 2001. Visual Methodologies - An Introduction to the Interpretation of Visual Materials. London: Sage Publication

[8] Satō, Masaaki, 2006. Mitos Honda: kejeniusan dan kebangkitannya, Vertikal, ISBN 978-1-932234-26-8"

[9] Santosa, Sigit. 2009. Creative Advertising. Jakarta: PT Elex Media Komputindo

[10] Setiyono, Budi. 2004. Cakap Kecap. Yogyakarta: Galang Press

[11] Sugiyono, 2015, Metode Penelitian Pendidikan Pendekatan Kuantitatif, 
Kualitatif, dan R\&D, Penerbit Alfabeta, Bandung.

[12] Sugiyono P.D., 2018, Metode Penelitian Kuantitatif dan Kualitatif dan R\&D Manajemen Strategi Pemasaran. Bandung: CV Pustaka Setia.

[13] Soraya, Iin. Modul Dasar-Dasar Periklanan, Universitas Bina Sarana Informatika Jakarta, 2019Widyatama, Rendra, 2006, Bias Gender Dalam Iklan Televisi, Yogyakarta: Media Pressindo

\section{Jurnal}

[1] Banindro, BS. 2011. Tinjauan Sosiohistoris Iklan Masa Kolonial (1930-1942). Jurnal Dekave Vol. 1 No. 1 Januari 2011. Institut Seni Indonesia Yogyakarta

[2] Erlitia, Novi, Potret Periklanan Di Media Massa Indonesia Novi Erlita Fakultas Ilmu Komunikasi Universitas Mercu Buana Jakarta, Jurnal Ilmu Ekonomi dan Sosial, Volume 5, Nomor 2, Juli 2016, halaman $199-210$

[3] Harsanto, PW. 2017. Fotografi dalam Desain Komunikasi Visual (DKV). Jurnal Imaji Vol. 15 No. 2 Oktober 2017. Universitas Negeri Yogyakarta

[4] Hadi, DW, Kasuma, Gayung, Propaganda Orde Baru 1966-1980, Universitas Airlangga, Jurnal Verleden, Vol. 1, No.1 Desember 2012: 1 - $109 \mathrm{Hal} 45$

[5] Hereyah, Yoyoh Iklan Mobil Di Media Cetak Analisis Elemen Copywriting Dan Visualisasi Di Majalah SWA Jurnal Visi Komunikasi Volume 13, No. 02, November 2014: 169 - 184

[6] Kertamukti, R. 2010. Komunikasi Visual Iklan Cetak Rokok di Indonesia Kurun Waktu 1950-2000. Jurnal ASPIKOM Vol. 1 Juli 2010. Universitas Muhammadiyah Yogyakarta

[7] Ramadhan, IR. 2015. Perkembangan Iklan Media Cetak dan Pengaruhnya terhadap Modernisasi di Jawa (1930-1942). Fakultas Ilmu Sosial, Universitas Negeri Yogyakarta

\section{Pertautan}

https://dgi.or.id/dgi-archive/gaya-visual-fotografidalam-iklan-cetak-di-surat-kabar-kompas1965-2009

https://databoks.katadata.co.id/datapublish/2018/ 01/31/inilah-pertumbuhan-ekonomiindonesia-sejak-1961

https://www.indonesiainvestments.com/id/budaya/ekonomi/keajaiba n-orde-baru

http://andiyunanto.blogspot.com/2013/05/normal -0-false-false-false-en-us-x-none_23.html https://boomeebbn.wordpress.com/2011/05/30/p erkembangan-advertising-di-indonesia http://zonamotorid.blogspot.com/2017/09/suzuki -fr70-legenda-motor-bebek-pertama.html https://www.webike.id/news/10-fakta-sejarahsuper-cub-yang-harus-kamu-ketahui

https://kumparan.com/ilham-bintang/artis-danachristina 1w8h8RJmL39/full

https://www.fimela.com/fashionstyle/read/3514571/mix-amp-match-mantelbulu-stylish-ala-para-selebriti-untuk-musimhujan

https://www.suara.com/lifestyle/2019/01/11/0 65500/baret-topi-militer-yangbertransformasi-jadi-item-fesyen

\section{Ucapan terimakasih}

Disampaikan kepada LPPM ISI Yogyakarta yang telah mendanai penelitian skim Pemula ini di tahun 2021. Tidak lupa kami sampaikan ucapan terimakasih yang tak terhingga kepada Dr. Nur Sahid, M. Hum. dan Dr. Ahmad Nizam, M.Sn. yang telah mereview penelitian ini hingga paripurna. 